\title{
Research on The Collaborative Development of the Pension Real Estate in Beijing, Tianjin and Hebei Based on the SWOT Theory
}

\author{
Liu Wencheng \\ School of Management \\ Tianjin University of Traditional Chinese Medicine \\ Tianjin, China \\ lwclwtg2016@163.com \\ Wang Lu \\ School of Management \\ Tianjin University of Traditional Chinese Medicine \\ Tianjin, China
}

\author{
Wang Xiaofang*(Corresponding Author) \\ School of Management \\ Tianjin University of Traditional Chinese Medicine \\ Tianjin, China \\ 1468630344@qq.com \\ Liu Cai \\ School of Management \\ Tianjin University of Traditional Chinese Medicine \\ Tianjin, China
}

\begin{abstract}
The thesis mainly studied the current situation of aggravation of aging problem in our country and the development of the pension real estate with literature survey method. For solving this problem as well as to put forward the pertinent suggestions for the innovative development of the pension real estate in this region, the Beijing-Tianjin-Hebei cooperation strategy is adapted to promote innovation of the pension real estate. According to this study, we find that the current problems are resulted from underdeveloped supporting facilities, separated medical insurance reimbursement system, traditional concept of retirement and economic level of the family and so on. These reasons restrict development of the pension real estate in Beijing-Tianjin-Hebei Region. In the end, in order to construct the functional area of the economy of Beijing - Tianjin Hebei region. We should promote the complementary advantages of resources in this region and the docking system of the pension insurance, renew the traditional concept of the elderly pension.
\end{abstract}

Keywords-Beijing-Tianjin-Hebei Region; pension real estate; coordinated development strategy

Beijing-Tianjin-Hebei region is located in the middle of the rim of the Bohai Sea region. The region has superior geographical position, abundant resources and dense population. The relevant data show that the aging population in Beijing and Tianjin is accelerating at an annual rate of more than 3\%. By the end of 2015, the population aged 60 and above accounted for $15.11 \%$ of the resident population in Hebei province [1]. As of July 2015, the average population aging rate in Beijing, Tianjin and Hebei area has exceeded $8.47 \%$, which undoubtedly is a heavy burden on our society, economy and other aspects of our country. In the face of the worrisome population structure and the increasing trend of the population aging in the Beijing-Tianjin-Hebei region, it is clearer that the urgency of the three cities' cooperation in the development of the pension service industry.

\section{Present Situation of Pension Real Estate in JinG-JiN- JI REGION}

In 2014, the government put forward the integration policy of Beijing, Tianjin and Hebei, which enabled Beijing, Tianjin and Hebei to fully coordinate the different advantages of local resources and collaborate with each other, reciprocate each other. Therefore, three regions can achieve the common development and a win-win result [2]. It will correspondingly promote the coordinated development of the pension industry in Beijing, Tianjin and Hebei. As can be seen from Table 1, urbanization rate, per capita GDP, the average retirement wage and the average price of commercial housing in Beijing and Tianjin are much higher than in Hebei. So this policy can also promote the focus of the pension industry development of Beijing-Tianjin-Hebei to the Hebei region tilt. However, the current Beijing-Tianjin-Hebei pension industry also appeared some problems in the development process such as the immature pension infrastructure facilities, inconvenience of cross-regional reimbursement for medical insurance, uneven standard of pension services, low level of human service experience and so on. Therefore, under the coordinated development of Beijing - Tianjin - Hebei region, discussing the current situation and problems of pension real estate and analyzing the development of the pension industry in Beijing Tianjin - Hebei region with the perspective of the SWO are very necessary and urgent.

See TABLE I. 
TABLE I. OVERVIEW OF BEIJING,TIANJIN AND HEBEI

\begin{tabular}{|c|c|c|c|c|c|c|}
\hline Region & $\begin{array}{l}\text { Population aging } \\
\text { rate(As of July } \\
2015)\end{array}$ & $\begin{array}{c}\text { Average } \\
\text { retirement } \\
\text { wage(Yuan) }\end{array}$ & $\begin{array}{c}\text { Urbanization } \\
\text { rate(2014) }\end{array}$ & $\begin{array}{l}\text { The average } \\
\text { number of a } \\
\text { family(2014) }\end{array}$ & $\begin{array}{c}\text { GDP per } \\
\text { capita(2014) }\end{array}$ & $\begin{array}{c}\text { Commercial } \\
\text { housing price } \\
\left(Y u a n / \mathrm{m}^{2}\right)\end{array}$ \\
\hline Beijing & $8.7 \%$ & 3355 & $86.35 \%$ & 2.49 & 99995 & 18833 \\
\hline Tianjin & $8.5 \%$ & 2295 & $82.27 \%$ & 2.62 & 105231 & 9219 \\
\hline Hebei & $8.2 \%$ & 2043 & $49.33 \%$ & 3.20 & 39984 & 5131 \\
\hline
\end{tabular}

\section{SWOT ANALYSIS ON THE DEVELOPMENT OF PENSION SERVICES IN BEIJING, TIANJIN AND HEBEI}

\section{A. Analysis on the internal advantages of pension industry development}

\section{1) The Complementary Resources of Beijing - Tianjin -} Hebei Region

The prosperous economy, excessive growth of the aging population and urbanization and high population density in Beijing and Tianjin has caused a heavy pressure on population. On the contrary, Hebei as a good ecological barrier in Beijing and Tianjin, the landscape is beautiful and the land price is relatively low. At the same time, relocation of a large number of pension research institutions and health care institutions improves the standard of scientific research on pension industry development and health care in Heibei. For the above reasons, it is highly feasible to develop the high quality of Pension Real Estate in Heibei, which is the nearest region to Beijing and Tianjin. And attract the elderly of Beijing and Tianji to relocate in Heibei. The current economic development in Hebei is relatively backward, and the surplus labor force is much. If the government and organizations at all levels in the region can train these surplus labor force systematically and increase the financial subsidy of the pension care workers, they can attract more labor to join the pension care industry. There are a lot of pension agencies with a generally high degree of marketization in Tianjin. Pension communities develop rapidly as well in this city. With regard to Tianjin's booming economy, abundant land resources, large number of pension communities and the project of pension area development, including Changgeng agedness apartment, the old club in Shanzhen and other large-scale pension communities, Tianjin is able to provide us a useful reference on how to construct pension well[4]. Beijing is the most important market for pension real estate because of its highly developed economy, higher average personal retirement salary and a large number of aging populations. What's more, Beijing has leading health care technology in China and the better quality of pension service, which can provide support to Tianjin and Hebei. According to the above analysis, it is clear that Beijing, Tianjin and Hebei should make use of their comparative advantages respectively in order to achieve complementary advantages, develop the distinctive pension service agencies and ensure the resources of three region and each region's advantages can be fully used and complemented.

\section{2) Supporting Policy of Beijing, Tianjin and Hebei}

Since 2010, Beijing, Tianjin and Heibei have held pension service meetings many times for deployment and arrangement of pension work. The meetings also provide a number of supporting policies on pension service industry. For instance, in September 2013, the State Council issued the landmark policy-"Opinions on Accelerating the Development of pension service industry", which made systematic plan and comprehensive arrangements for accelerating the development of the pension service industry. Tianjin also has issued "Notice on Supporting the Development of the City Pension Services, Promoting Re-employment of Laid-off Workers" and "Views on Accelerating the Development of Pension Services in Tianjin " and other policies. By 2015, Tianjin basically formed a "973" pension service pattern, that is, 97\% of the city's elderly population live at home, the rest of $3 \%$ of the elderly live in pension agencies. All these indicate that efforts of Tianjin to promote the integration of Beijing-Tianjin's pension services. Similarly, governments at all levels and relevant departments in Hebei Province has also issued various policies such as "Opinions on Accelerating the Construction of Pension Service System”, "Supplementary Measures for the Evaluation of the Pension Service System in Hebei Province (Trial Implementation)”, “'Twelfth Five - Year' Plan on Construction of Basic Pension Service System in Hebei Province ", "Opinions on the Implementation of the Award for Pension Service Institutions”, “ 'Twelfth Five - Year' Plan on the Development of Aging Career in Hebei "[1]. Under the context of the coordinated development of Beijing, Tianjin and Hebei, these policies of promoting the development of pension services are an important guarantee for the pension service system of Beijing, Tianjin and Hebei. Besides, these policies also promoted the development of the pension service industry effectively. Thus, it is a good opportunity for three regions to develop the pension services coordinately.

\section{B. An analysis of the internal disadvantages of pension industry development}

\section{1) Immature Pension infrastructure facilities}

Up to now, a lack of mature operational management model and the integration of professional medical support and pension services model can be seen from the following three aspects. First, different from the downtown location of foreign endowment real estate, Beijing-Tianjin-Hebei endowment real estate prefers to suburbs. The lack of interaction with the surrounding communities results in inconvenience of children's visit and medical treatment, which also bring a sense of loneliness to the elderly. Second, it is the shortage of professional pension service personnel, especially nurses, psychological counselors, health care workers and other positions. Due to the low salary of nursing staff, the intensity of work, the elderly nurses job recruitment is more and more 
difficult, and some hired nurses are without professional training, which to the detriment of the service quality. Third, it is the lack of adequate health, culture and sports facilities. The critical problem is the lack of formal health care institutions. Some clinics are only responsible for the supply of basic medicines and health checkup, and few of them are eligible for government health insurance reimbursement. In addition, some pension real estate does not really take the actual needs of the elderly groups into consideration when they try to improve the supporting facilities and to make projects more suitable for the elderly. In consequence, there is no difference between seniors' housing and ordinary residence.

2) Inconvenience of cross-regional reimbursement for medical insurance

Currently, there are institutional barriers and poor accessibility of medical insurance in Beijing, Tianjin and Hebei. Institutional barriers are mainly manifested in the basic medical insurance system in three regions because of the big differences of institutions between them. It is difficult to achieve the integration of cross-regional medical insurance system[5]. First of all, there are differences in classification of the basic medical insurance system of Beijing-Tianjin-Hebei. The system structures are different. Secondly, there are differences in insurance types of flexible employments. Accordingly, the classifications of medical insurance and payment standards are different as well. Lastly, there are different levels of overall planning of medical insurance between Beijing, Tianjin and Hebei. The accessibility of medical insurance is mainly reflected in the transfer of medical insurance and medical treatment. Hence, some problems appeared. For example, when people get medical treatment across provinces, they are unable to get insurance reimbursement directly. The requested qualifications of transferring medical insurance into Beijing and Tianjin are too strict and personal burden is too heavy. Rural residents have a double burden on insurances payments. Employees of Outflow only transfer personal accounts, which caused part of the loss of interest and a missing of the method to account for the required years for transfer of insurance payment. Besides, improving the accessibility of medical insurance may lead to health care insurance immigration. Immature medical insurance information sharing will also cause the health insurance department's high regulatory pressure and operating burden.

\section{An analysis of the external opportunities for the development of the pension industry}

1) The trend of aging population, empty nest and disability of the elderly in Beijing, Tianjin and Hebei

The aging population of Beijing, Tianjin and Hebei has grown rapidly since the beginning of the 21st century. The data show that the aging population in Beijing and Tianjin is accelerating at an annual rate of more than three percentages. By the end of 2010, the total number of the population who has Beijing's household registration is 1257.8 million. Among them, the number of the elderly population who aged from 60 to 80 is 2.35 million, accounting for $18.7 \%$ of the total population; the elderly population aged above 80 is 35.1 million, accounting for $2.8 \%$ of the total population. By the end of 2010, the elderly population aged 60 and over in Tianjin has reached 1.764 million, accounting for $17.91 \%$ of the total population of the city's household, ranked the third in major cities of the country, following by Shanghai and Beijing, by the end of 2010, the elderly population in Hebei Province reached 989 million, accounting for $14 \%$ of the total the population of the province[6]. In summary, the increasing trend of the aging population in Beijing, Tianjin and Hebei provides a huge market for three places to develop the pension service industry. Furthermore, the single child age also makes our "empty nest" elderly phenomenon more frequently to appear. According to the "Report on the Health Status of Beijing Population" issued by the Beijing Municipal Health Commission, as of the end of 2014, population aged 60 and above has reached 301 million, accounting for $22.6 \%$ of the population. Among them, the elderly "empty nesters" accounted for $50 \%$, and the disabled elderly accounted for 20\%. Population of Tianjin aged 60 and above reached 215.42 million, accounting for $21.18 \%$ of the registered population. Among them, the elderly "empty nesters" accounted for 39\%, and the disabled elderly accounted for $7 \%[7]$. In the next few years, aging, empty nest, disability of the elderly groups will lead to explosively growth of demand for pension services in Beijing and Tianjin. In addition, with the medical institutions, rehabilitation facilities and training institutions and other infrastructure construction, pension agencies construction investment also has a large market. The above data indicate that the bright development prospects of the pension industry in Beijing, Tianjin and Hebei.

2) Traffic integration development in Beijing, Tianjin and Hebei region

At present, transportation in Beijing-Tianjin-Hebei region is convenient and well-developed. It has formed a regional integrated transportation network with the Bohai Sea as the leading port, the railway as the backbone, the road as the basis, the air transportation and the pipeline transportation combined. There are 35 highways within the region and more than 280 traffic roads, connected to the arterial traffic of the provinces, which almost covering the 3 hours of 11 districts of the urban Beijing, Tianjin and Hebei. More than 900 traffic lines in provinces and cities have been set up. The number of operating buses is reached more than 2200[8]. By 2020, the BeijingTianjin-Hebei traffic integration plan is to construct the 9000 km highway and the main cities' 3-hour traffic circle in Beijing, Tianjin and Hebei[9]. The development of these traffic lines has made travels between Beijing and Tianjin more convenient. What's more, the travel time will be shortened. If the elderly of Beijing and Tianjin live out of their life after retiring in Hebei, the traffic problem can be easily solved when the elderly want to go back and get medical treatment in hometowns or when children want to visit the elderly in Hebei pension institutions.

\section{An analysis of the external threats to the development of the pension industry.}

1) Constraints of traditional pension concept and the restrictions of family economic level

Now the young people who work in Beijing, Tianjin and Hebei are incline to be attracted in and settle there. While at the same time, there is still "raising children" concept existing in some elder people who are often reluctant to live in those big cities. Moreover their children are living too far to be taken 
good care of by if they choose to buy old-age real estate, which increases the difficulty of the elder people pension in Hebei province. Moreover for some elder people, "An soil relocation" still works. Although the pension of Hebei Province off-site is cheap, and the environment is beautiful, their pension concept has not changed, having been effected by the traditional Chinese culture and thought, they are still not willing to leave the original residence. The wishes of the elderly in Beijing and Tianjin have also raised the challenge of Hebei Province to undertake the transfer of the pension service industry in Beijing and Tianjin. In addition, there are some elderly parents now doting their children, what's more, the over-protection and expectations are too high which only lead to what we call "Boomerang Generation”. So finally, the children are not only failing to take care of their parents, they need to get parents' support. Pension was used for raising their children so they do not have the additional economic capacity to buy pension services.

\section{2) Uneven of the service level in Beijing-Tianjin-Hebei} pension

At present, the construction of nursing staff in the pension service of Beijing-Tianjin-Hebei is seriously lagging behind. The current pension service team presents the following features: non-professional, and non-standard. Practitioners are basically from the urban laid-off workers and rural surplus labor force. Their education level is not high, and they are aged without professional training and lack of qualification certificate, job certificate, etc., resulting in their service is neither professional nor scientific, so the interests of the elderly are often being damaged. Even worse, it happened on both sides of the service disputes with constantly friction. In addition, according to the calculation of the international common age and caregiver ratio of 3: 1 , our country needs at least 10 million caregivers. But the current national welfare agencies only own 22 million workers with only 20000 people[10] having the qualification. It fails to fill the gap of the potential gap of ten million disabled elder people. It also can't suit the nursing needs of the elder people which lead to the decline of the quality of pension in Beijing - Tianjin - Hebei region. Finally, it restrains the development of the industry of aged-proiding.

\section{Suggestions FOR the DeVElopMent Of THE PENSION REAL ESTATE SERVICE INDUSTRY BASED ON SWOT}

\section{A. The complementary advantages of resources in Beijing- Tianjin-Hebei region}

The problem of aged-providing is very serious which has entered a high-speed development stage. Therefore, it is urgent to solve the problem of the elderly in Beijing, Tianjin and Hebei. It needs the combination of the advantages of resources in the Beijing-Tianjin-Hebei region, and we should make full use of favorable conditions to realize the complementarity of the three to provide favorable conditions for improving the oldage population.

Therefore the respective geographical advantages in Beijing, Tianjin and Tianjin region can be fully complementary. The regional economic development strength is living in the forefront of the country, only on economic resources, especially the development of pension services required by the conditions of the terms of the two cities in the absence of any problems[11]. However, there are a number of populations caused by traffic congestion, environmental pollution, high housing prices and social problems in the three regions. In contrast, Hebei Province, even the economic development is at a low level which cannot support the development of pension services, but its geographical location is closer to Beijing and Tianjin, adding to the convenient transportation, and cheap land, lower prices, more importantly, its beautiful environment and natural environment which is suitable for the development of pension real estate. Some cities such as Chengde, Qinhuangdao, Baiyangdian, Beidaihe and other vibrant tourism and leisure scenic spots, are conducive to the development of unique pension industry.

\section{B. Promotion of the docking system of pension insurance in Beijing - Tianjin - Hebei region}

The key to achieve living out of the life in retirement in cross-region is to release the restricted policies and systems of medical treatment and pension insurance. With the help of the development of Beijing-Tianjin-Hebei's cooperation as a national strategy, the three regions' governments should effectively carry out the coordinated management of social security integration. In particular, to support the establishment of the integrated coordination mechanism for the pension insurance system and give its corresponding management authority[12]. On the one hand, through the government's support, modification or formulation of the relevant laws and regulations and living out of one's life in a cross-region, we can unify pension service standards of the three regions[4] and implement with no barriers. On the other hand, through the establishment and improvement of the pension insurance management information network platform, to achieve the elderly health insurance information sharing, and high disposal efficiency of pension insurance. In addition, in order to improve the management of relevant institutions capacity, we should strengthen the educational quality and improve the technical knowledge of the staffs.

\section{Renewal of the traditional concept of pension model into a modern one.}

The simplification of family structure has a certain impact on the traditional family pension model, so it is necessary to change the traditional concept, and to implement a modern pension model. Collaboratively develop the new trend of "offsite pension". With the influence of the increasingly trend of the "inverted triangle" family structure, the government should increase the pilot projects and promotion of a new pension industry operating model. Taking the advantages of the beautiful environment, convenient transportation and others, to attract and promote pension real estate and public recognition. In view of the main problems and reasons of restricting the development of the pension industry, we must develop a forward-looking pension industry policy.

We should take feasible measures immediately towards the problems appeared in the operating process. For example, family economy is a great resistant power for developing of the 
new pension model-pension real estate. We can ease family economic pressure through housing endowment and investment of new pension model. "The housing endowment" model refers to the elderly can rely on the spare real estate as a lease, sale or mortgage to earn pensions. To buy or rent the pension community for reducing of the economic burden of their children, as well as their own pension problems. "Investment Pension" model is that through the operation of pension funds to achieve the increasing value of the funds. It is a way for the elderly to have more security funds[7]. Good management of the elderly pension, as assets into stocks, bonds and banks or the purchase of commercial pension insurance, etc. is able to help them achieve the preservation and increasing of pension funds.

\section{Construction of the characteristics and functional pension industry areas in Beijing - Tianjin - Hebei.}

Beijing and Tianjin region make use of their own medical advantages such as technological advantages, personnel advantages, scientific research advantages and other advantages to achieve integration of resources in Beijing, Tianjin and Hebei. Through medical personnel training, medical technology guidance, medical service quality supervision to enrich the medical resources in Hebei Province, improves the quality of medical care and train medical professionals. Finally, achieve mutual benefit and win-win effect.

Cooperation of Jing-Jin-Ji provides opportunities to develop the characteristic function area of the pension industry. To encourage the development of the pension services and pension service institutions. Let social capital invest into the social pension process for meeting the basic needs of the elderly pension. From the perspective of social trust, public participation and social networking, etc., to establish and improve the elderly services, the elderly medical care system. Supporting the elderly groups to carry out various social activities with the unique set of "home + community + Institutions "as one of the new pension model. Above all, we can make the Beijing-Tianjin-Hebei region pension industry booming.

\section{REFERENCES}

[1] Sun Jianfu, Dai Luwei. Conditions, objectives and principles of the development of the pension services industry in Jing-Jin-Ji region [J]. Economic Research Reference, 2015, vol. 37. pp. 41-46.(In Chinese)

[2] Li Qing. Xi Jinping hosted a forum to listen to the joint development work report of Jing-Jin-Ji. [EB/OL]. http://news.xinhuanet.com/politics/201402/27/c_126201296.htm,20140207/20160701.(In Chinese)

[3] National Bureau of Statistics. China Statistical Yearbook 2015. [EB/OL] [20160701]. http://www.stats.gov.cn/tjsj/ndsj/2015/indexch.htm.(In Chinese)

[4] Zhao Pei Pei. Research on the coordinated development of pension service industry under the background of the integration of Beijing, Tianjin and Hebei [D]. Hebei University. 2015.(In Chinese)

[5] Hanlu. Research on the coordinated development of Beijing, Tianjin and Hebei Medical Insurance System [D]. Beijing Jiaotong University. 2016.(In Chinese)

[6] Zhang Shouying. Analysis of social construction in Beijing in 2010 [M]. Beijing. Social Science Literature Press. 2010.(In Chinese)

[7] Li Jing, Han Xiaohu. Investigation on the Willingness of Providing for the Elderly in Beijing and Tianjin in the Background of the Development of Beijing - Tianjin - Hebei [J]. Industry and Technology Forum, 2016, vol.11. pp. 133-134.(In Chinese)

[8] Feng Mei, Liu Yao. The Development of Characteristic Industry in Beijing, Tianjin and Hebei and the Integration of Regional Traffic [J]. Journal of Hebei Normal University (Philosophy and Social Sciences Edition), 2011, vol. 56. pp. 9-64.(In Chinese)

[9] [9] Wu Qiong, Liu Junping. Analysis on the Development of the Pension Service Industry in Hebei Province from the Perspective of Industrial Connection between Beijing, Tianjin [J]. Journal of Tangshan Teachers College.2015,vol. 37. pp. 144-147.(In Chinese)

[10] Zhao Dongxia, Li Laizhi.The SWOT Analysis of the Development of China's Pension Industry in the Only Childhood[J].Research on Financial and Economic Issues.2013, vol. 35. pp. 30-34.(In Chinese)

[11] Li Jing, Wang Mei.A Probe into the Profit Model of the pension Industry - Taking the Pension Industry in Beijing, Tianjin and Hebei as an Example[J].People Forum. 2016, vol. 28. pp. 3226-228.(In Chinese)

[12] Zhang Jinfeng. A Study on the Tactics of the Basic Endowment Insurance System in Beijing, Tianjin and Hebei Provinces [J]. Journal of Tianjin Administration Institute. Journal of Tianjin Administration Institute. 2016, vol. 18. pp. 54-60.(In Chinese) 